\title{
Intellectualization of determination of electrical loads in city electric networks
}

\author{
A. G. Saidkhodjaev ${ }^{1}$, B. Kh. Ametova ${ }^{2}, M . M$. Mamutov $^{2}$ \\ ${ }^{1}$ Tashkent State Technical University named after Islam Karimov, 100095, Uzbekistan, Tashkent, University St. 2 A. \\ ${ }^{2}$ Karakalpak State University, 230100, Uzbekistan, Nukus, Ch. Abdirov St.1.
}

\begin{abstract}
This article illustrates new methods for automatically fixing and determining the calculation loads of electrical consumers, in particular the maximum load. The accuracy in the calculations is increased taking into account several factors affecting the maximum load values. It also offers a method and algorithm determination of the maximum electrical loads in urban electrical loads.
\end{abstract}

The increase of electric stations and electric transferring channel capacities, also the advancement of culture of power system operation, the application of new computing technologies and automatic system controlling the technological processes, all the above leads to the necessity of achieving precise calculation, control and increased accuracy of power measurements.

There are large number of "levels" of power control, that could include simple and detailed researches, that are often accompanied by trial tests and planned examinations. The preliminary tests of electric power represent important step in accumulating the prior data.

In order to carry out the examinations there are eight main steps have to be taken:

1. Work out the projected plan, determine important zones and centers of the company and household, also planning the effective timing.

2. Compile major data on company's (household's) power consumption, production (household) information, using standard format.

3. Carry out necessary changes and take measures to obtain the data concerning the consumption and its profitability.

4. Calculate the power balances and efficiency per consuming element and also per whole consuming unit.

5. Establish the technique of technical service using the up-to-day recommendations that would lead to power savings and raise the profitability.

6. Determine the possibilities and ways of power savings, without requiring considerable investments.

7. Work out an exact plan of actions and events in order to execute recommendations on power savings, economy and reduction of power losses.

8. Prepare the report with the given analysis of power control and necessary recommendations on actives concerning the power economy. [4]

For control over the electric power usage, there are over 540 thousands of users in Tashkent city, who has meters of following types: active and reactive power source, inductive, single and triple phase, three and four transmitters, with the current and voltage transformers.

The technical data of the meters according to the certification proved that they have accuracy level 2 , in other words the maximum inaccuracy of meter measurement allowed is up to 2 percent's, which in Republic scale totals in 5,16 billion per year. The improvement in accuracy of measuring the output and power requires the optimal exploiting of power systems. Also it needs control over the peculiarities of power processes in power saving» systems during the heaving loads that deviate the shape of the current line and cause the current vibrations and change in directions. The accuracy measurement in the power system, depends not only on the class of the meter, but also on measuring structure of the device, i.e. how precise the device can indicate the distorted load characteristics. Therefore, one of the main problems of control and registration is the issue of choosing the registration and control systems with the accuracy levels of $0.2,0.5,1$. [5]

Technology wise this requirement are met in the following registration systems: "ALFA"; automatic control and registration system of electric power (ACRSE); "EMKOS"- automatic system of commercial tele registration of gas, steam, electricity, coal, coke, water, petroleum products, and other various types of devices presented by "SIEMENS" and «NEVA» systems. The multifunctional micro processing electric power meter of "ALFA" type is accuracy class 0.2 and 0.5 , designed for measuring the active and reactive power, current, cosine $\mathrm{cp}$, current and full power.

The main functions of the "ALFA" MET program are:

Corresponding author: anvarsaidkhodjaev@yandex.com 
- Reading of commercial data from meter in the automatic mode;

- Establishing and supporting the database, storing the full information on the company's ACRSE system;

- Displaying the calculated for the definite time period power data;

- Creating various types of reports, using the read of the meter data.

The "ALFA" system is used on large industrial enterprises with 5, 10, 50, 100 consumers. Quite safe and convenient in operating, the system supplies accurate measurement of all major electric data of electric power consumption for any time period, during respectively the last 3 years of operating. The system could get connected to the control computer of Uzbekistan State Power Control through the modem, which allows charging the users of electricity on time. Currently such kinds of device are installed on large enterprises.

The "EMKOS» is the more multi-purpose system of commercial tele registration of power, designed to set automatic distant registration for consumption of various types of power and has the following operating features:

- Carries out the mathematical analysis of registration results, consequently identifying the electric power

consumption tendency and organizing the recommendations on more rational usage of electric power resources;

- Manages the presented tasks with the same efficiency for any type of power and power sources, including

gas, steam, electricity, coal, coke, water and petroleum products.

This system is mainly installed on large industrial enterprises, large public and institutions, that consume considerable amount of various types of electric power. This system is widely used by the electric power producing and distributing enterprises. It allows to the 525 percent of electric power.

The information once downloaded into the "EMKOS" database, can be then repeatedly used and processed by various programs sub-module algorithms, as for instance, for creating reports, graphs, carrying out graphic a mathematic analysis.

Thus, the "EMKOS» system carries out constant multi-channel accumulation, registration and safekeeping of the measured data, obtained from registering devices of electric resources (meters, usage meters), processes the data to present it in the form convenient for commercial inter-accounting and electric power consumption analysis.

Since the "ALFA" and "EMKOS" systems are expensive registration systems, they are currently installed only at large electric power sources and at industrial enterprises. [3]

The most interesting system for the public as well as for household sector electric power service registration and control can be the "Israelis" model of commercial registration based on the usage of plastic cards, similar to
VISA cards, that after preliminary payment to the back, can be inserted into the meter. The meter indicators the electric power consumption, also about the sum left on the card. The disadvantage of the system is its high price and uncertified crediting system of meters.

Combined, multi-functional | Dialog" meters from SIEMENS" have flexible and module meter structure, mechanism of reading off the optical interface, digital measurement system, communication channels, memory, clock and remote controlled information systems. These devices have a digital measurement system and allow measuring and controlling of the voltage, current, frequency, power, with the accuracy level of $0.2,-0.5$, 1. The disadvantage is the high price again. [3]

More than ten years are used the newest, technological and multipurpose information systems "NEVA" of SPF "Energosoyuz". The basis of the system "NEVA" is the block of registration and the control of normal and emergency operation and waste-account of energy carriers (BRCW). The elementary case of application of system "NEVA" is the modernization of old systems and creation of new systems of registration of emergency cases. Up to 64 analogs and up to 288 discrete signals can be connected to one oscillography. Signals will be automatically written down, transferred to the personal computer and submitted on the screen of the monitor in a comfortable way to the user. By the signals of currents and voltage from gauges, their working values in any point before-emergency, emergency and after- emergency process is calculated inside an oscillography by the programming way. Having connected to BRCW signals from switches and disconnection $\mathrm{s}$, it is possible to display a condition of the circuit of object on the screen of the personal computer. On any discrete entrance of BRKC it is possible to connect pulse inputs from counters of the electric power, water, gas, etc. which work under the program "ASKUE". In the system "NEVA" automatic formation of the daily sheet of a production schedule is made. The device for oscillography, measurements and the analysis of electric modes and quality of the electric power is included into the complete set. Power inspections ("Energy audit") of an electric part of industrial and energy supplying enterprises, inclusion of system "NEVA" in a local network of the enterprise, definition of a place of damage, registration of operations of the switching equipment and devises of relay protection and automatics, are opened for system "NEVA". Any events fixed by the system "NEVA", inclusion or switching - off of switches, operation of protection and automatics, start of an oscillography and many other functions are sounded with the help of the program "INFORMATOR". [3]

For the public and household sector of Uzbekistan the most acceptable is the Moscow "automatic integral measuring system of electric power economy" (AISE), which is cheaper and can be used for bot $\mathrm{h}$ the technical and commercial registrations of electric power resources and water expenditure. The AISE is installed in Moscow since 1998. All new apartment buildings built for the past 3 years have been supplied by the AISE. In Moscow this system is installed on 1600 objects and serving over 
160000 apartments, as well as in the industry. Simultaneously the large-scale measures are taken on transferring the city electric circuit to double tariff payment system. The nighttime period is established from 23:00 p.m. to 7:00 a.m... The discount night time tariff is 4 times less than the ordinary tariff. [2]

For the complex solution of task on electric power and water usage, from the actual consumption to the registration, the current data from the meters can be transmitted from AISE to the system of consumer payment reception at any time.

AISE represents the computerized radio-engineering complex with the adaptable structure for the particular application, by locating in the served territory.

AISE operates in the automatic mode (without the assisting personnel) on the level of apartments and enterprises, displaying the information on the computer screens in the controller's office. It uses the Complex of technical means (CTM), mass produced by the "ENEPEKO" for the technical and commercial registration and control over the electric power resource and water consumption. [3]

In this system old inductive meters can be replaced, without replacing the electric cable. In addition, the electronic system block is installed together with the main meter, thus increasing the accuracy of measurement. That's why this electronic single-phase, single tariff meter of type "SEB-1 M-l" is mostly used in the apartments. The electric power supply is impossible without accurate measurement of amounts produced, transferred and consumed electric power. Up to present days all the enterprises of Ministry of Electric power were structured subdivisions with the incomplete balance. The general balance was organized in general on the Ministry of Electric Power level and all the imbalances were covered up by each other. Today, after the recon structuring of the branch, when the balance of production, transportation and distribution is organized on each independent enterprise, the non-coverable imbalance will appear only due to the accuracy of measurement "level" of accuracy of the devices.

The important problem of registration and control is the issue of the measurement device (meter) ownership. At present time the meters are the properties of consumers. Thus the individual is not seriously interested in improving the existing situation of the system of registration, production, transportation and output of electric power. To restructure the registration it is necessary to put the registration means of electric power, heat, gas and water on the balance of power sellers. This would allow them replace the equipment with the technologically new system of registrations and control over the expenditures and payments.

The other, of no small importance peculiarity in electric power consumption is the change in the consumption structure.

According to the Hea State Electric Power control data, consumption structure of electric power for the years of 1970-1980 was composed of:

Population - $\quad 12-18 \%$

Public (communal) - $\quad 22-28 \%$

Industrial - $\quad 60 \%$
The main electric power system loads were regulated mainly by the large power consuming industrial customers. In the past 9-10 years the consumption structure has rapidly changed and looks like this:

Population $25-30 \%$

Public (communal) - $\quad 30-35 \%$

Industrial $40 \%$

In the general maximum the main burden is from the population. That is not limited according to the civil rights code, public and industrial burden, such as state financed institutions, water supply, transportation, heating plants, city electric, which have that same maximums with the general one. The real decrease of maximums is impossible; regulation is possible with the various tariffs application. [3]

The issue of identifying the necessary number of measurements for electric in household and public institutions should be based on the probability theory of a mathematical analysis, because the urban circuit load has a random nature and is supported by these laws. It should be mentioned that the change in the schedule of electric power loads in the household buildings depends on the normal law of distribution and requires a large number of measurements. As for the common consumers of public sector, where the nark schedule and the nature of the electric power loading have little change in time because it has insignificant difference configuration and schedule, the student distribution law could apply with taking into consideration the small portion out of large volume of data. Where the distribution $\mathrm{S}(\mathrm{t})$ is supported by the law of:

$$
S(t)=C\left(1+\frac{t^{2}}{n-1}\right)^{-\frac{n}{2}},
$$

The number " $n$ " in the student's distribution may lake any large or small number and the $\mathrm{S}(\mathrm{t})$ approaches the normal distribution law $\mathrm{P}(\mathrm{t})$ with the increasing " $\mathrm{n}$ ":

$$
P(t)=\frac{1}{\sqrt{2 \pi}} \cdot e^{-\frac{t^{2}}{2}}
$$

During the number of years there have been carried out a lot of test researches on electric power consumption for all the categories of household and public institutions considering various factors. Based on the measurements there was worked out an established whole set of common daily schedules of for household and public institutions.

The required number of measurements to obtain reliable initial data for calculating the load of the same type of consumers, according to the Student's distribution, is more than 60 . Therefore, measurements were carried out continuously at the same point of the electrical network for 8 days and at 8 objects of the same type, i.e. 64 measurements at the same point of the consumer.

The researcher has showed that the load on any element of city current is the functional of large number of random factors, their numerous combinations and time changes. Therefore, all the values, calculated of the 
base of electric power loads, will be values of probability functions for the random variable electric loads.

The structure and the nature of the electric load graphs, obtained by the experimental way for all the kindred consumer have the same tendency of changes. Thus the probable values of electric loads could be considered as the numeral characteristics of statistic distribution.

\section{Conclusion}

1. On the basis of researches, by the author, using the experimental way of typical daily diagrams and calculation method of the total mixed loading of nonuniform consumer's probable-statistical way, a technique and the program of calculation on computers of city networks was developed under a pressure voltage of 0 , $38 \mathrm{kV}$ and $6-10 \mathrm{kV}$ and at probable task of loadings. [1]

2 . Thus, the full cycle of calculation of the systems of electro supply of cities on lower and average hierarchy is created and is fully automated, starting from the initial data, calculation of city electric networks. The offered technique allows us to reveal a real mode regime of operation of a network for each hour and to make necessary calculations, including those that are related to optimization the mode selection of operations and elements of an electro supply system, and relying on the most authentic loadings considering changes in dynamics in time. The perspective power consumption and electric loadings can be received relying on the forecast methods, stated in [2]

3 . We have worked out the algorithm programs that would allow completely automate the whole design process and system projects of city electric power saving, with highly accurate data based on the probability statistical methods. There algorithms programs are based on the new technologies of control and registration the consumption of electric power.

4. The process of projecting electric networks is automated \& application of computers for calculating and projecting of electro supply systems considerably allows us to reduce terms of development of the project and to exempt the qualified no production personnel from mechanical non- creative work. Besides, quality of the project documentation and labor productivity of workers of the project organizations impartment settlement expenses are increases, in comparison with the expenses at projecting systems by a traditional technique.

\section{References}

1. A.Saidkhodjaev, B.Teshabaev, Leu. Patent number IAP 04216 ( IAP 2006 0404), (2010).

2. A.Saidkhodjaev, Power supply of cities. Textbook. T.: "Fan va texnologiya", 328, (2015)

3. A.Saidkhodjaev, Fundamentals of energy saving. Textbook. - T.: "Lesson Press", 320, (2015).

4. A.Saidkhodjaev, Methods and tools of the energy audit. Textbook. - T.: "Noshirlik yog'dusi", 182, (2015). 5. A.Saidkhodjaev, Issues and prospects of urban power supply systems development. Monograph. - T.: "Fan", 256, (2012). 